\title{
New Flavone C-Glycosides from Scleranthus perennis and Their Anti-Collagenase Activity
}

\author{
Katarzyna Jakimiuk $^{1}$, Jakub W. Strawa ${ }^{1}\left(\mathbb{D}\right.$, Sebastian Granica ${ }^{2}\left(\mathbb{D}\right.$ and Michał Tomczyk ${ }^{1, *}$ (D) \\ 1 Department of Pharmacognosy, Faculty of Pharmacy with the Division of Laboratory Medicine, \\ Medical University of Białystok, ul. Mickiewicza 2a, 15-230 Białystok, Poland; \\ katarzyna.jakimiuk@umb.edu.pl (K.J.); jakub.strawa@umb.edu.pl (J.W.S.) \\ 2 Microbiota Lab, Center for Preclinical Studies, Department of Pharmacognosy and Molecular Basis of Phyto \\ therapy, Faculty of Pharmacy, Medical University of Warsaw, ul. Banacha 1, 02-097 Warsaw, Poland; \\ sgranica@wum.edu.pl \\ * Correspondence: michal.tomczyk@umb.edu.pl; Tel.: +48-85-748-56-94
}

Citation: Jakimiuk, K.; Strawa, J.W.; Granica, S.; Tomczyk, M. New Flavone C-Glycosides from Scleranthus perennis and Their Anti-Collagenase Activity. Molecules 2021, 26, 5631. https://doi.org/ $10.3390 /$ molecules 26185631

Academic Editors: Nawaf Al-Maharik and Fengqing Yang

Received: 20 July 2021

Accepted: 15 September 2021

Published: 16 September 2021

Publisher's Note: MDPI stays neutral with regard to jurisdictional claims in published maps and institutional affiliations.

Copyright: (c) 2021 by the authors. Licensee MDPI, Basel, Switzerland. This article is an open access article distributed under the terms and conditions of the Creative Commons Attribution (CC BY) license (https:// creativecommons.org/licenses/by/ $4.0 /)$.

\begin{abstract}
Three new flavone glycosides, one known flavone glycoside, and the phenolic derivative apiopaenonside were isolated and identified from the ethyl acetate fraction of the aerial parts of Scleranthus perennis. The planar structures were elucidated through extensive analysis of UV-Vis, IR, and ${ }^{1} \mathrm{H}$ NMR and ${ }^{13} \mathrm{C}$ NMR spectral data, including the 2D techniques COSY, HSQC, and HMBC, as well as ESI mass spectrometry. The isolated compounds were established as 5,7,3'-trihydroxy$4^{\prime}$-acetoxyflavone-8-C- $\beta$-D-xylopyranoside- $2^{\prime \prime}$-O-glucoside (1), 5,7, $3^{\prime}$-trihydroxy- $4^{\prime}$-methoxyflavone8-C- $\beta$-D-xylopyranoside- $2^{\prime \prime}$-O-glucoside (2), 5,7-dihydroxy- $3^{\prime}$-methoxy- $4^{\prime}$-acetoxyflavone-8$C$ - $\beta$-D-xylopyranoside- $2^{\prime \prime}$-O-glucoside (3), 5,7-dihydroxy- $3^{\prime}$-methoxy- $4^{\prime}$-acetoxyflavone- $8-C-\beta$-Dxylopyranoside-2" $-\mathrm{O}-\left(4^{\prime \prime \prime}\right.$-acetoxy)-glucoside (4), and apiopaenonside (5). Moreover, all isolated compounds were evaluated for anti-collagenase activity. All compounds exhibited moderate inhibitory activity with $\mathrm{IC}_{50}$ values ranging from 36.06 to $70.24 \mu \mathrm{M}$.
\end{abstract}

Keywords: Scleranthus perennis; Caryophyllaceae; flavonoids; isolation; scleranthoside; C-glycosides; collagenase

\section{Introduction}

The genus Scleranthus L. (Caryophyllaceae) comprises 11 named species divided into two sections, Scleranthus and Mniarum. Scleranthus includes three endemic species to Europe, Western Asia, and North Africa (S. annuus, S. perennis, S. uncinatus), as well as three Australian endemic species (S. diander, S. pungens, S. minusculus). The plants of Scleranthus are widespread perennial herbs occupying mainly dry, sandy, or disturbed habitats [1,2]. Previous phytochemical studies have revealed the presence of flavonoids in S. uncinatus [3,4]. Furthermore, phenolic acids have been isolated from S. perennis water/alcoholic extracts, while sapogenins, tannins, and sterols were identified from butanol extracts $[5,6]$. S. annuus water/alcoholic extracts are a source of phenolic acids and flavonoids [7]. S. perennis has not been well studied, and thus its phytochemical and pharmacological data are scarce. In folk medicine, this plant has been used for veterinary purposes as a remedy for animals that display a fluctuating temperament [8].

In our continuing phytochemical investigation of this plant, we isolated five compounds. According to high-performance liquid chromatography coupled with diode-array detection and mass spectrometry (UHPLC-DAD-MS) analysis and the UV-Vis spectra, four of the obtained structures were classified as derivatives of flavones $[9,10]$ and one was identified as a paeonol derivative. In the present work, we performed investigations and identified $C$-glycosylated luteolin derivatives and apiopaenonside in an ethyl acetate fraction of $S$. perennis. For these compounds, ${ }^{1} \mathrm{H}$ NMR and ${ }^{13} \mathrm{C}$ NMR analyses, including the 2D techniques COSY, HMBC, and HSQC, as well as UV-Vis, IR, HR-ESI-MS, product 
ion scan, and acid hydrolysis, were performed. To the best of our knowledge, three of the isolated compounds are new chemical structures found in the plant kingdom. The present communication addresses their isolation and structural elucidation as well as bioactivity evaluation of these compounds.

\section{Results and Discussion}

The preliminary LC-MS screening of the ethyl acetate fraction from the dried aerial parts of S. perennis showed the presence of polyphenol derivatives [9]. Thus, the ethyl acetate fraction was separated multiple times by preparative, providing four flavone derivatives (1-4) and one phenolic derivative (5) (Figure 1).

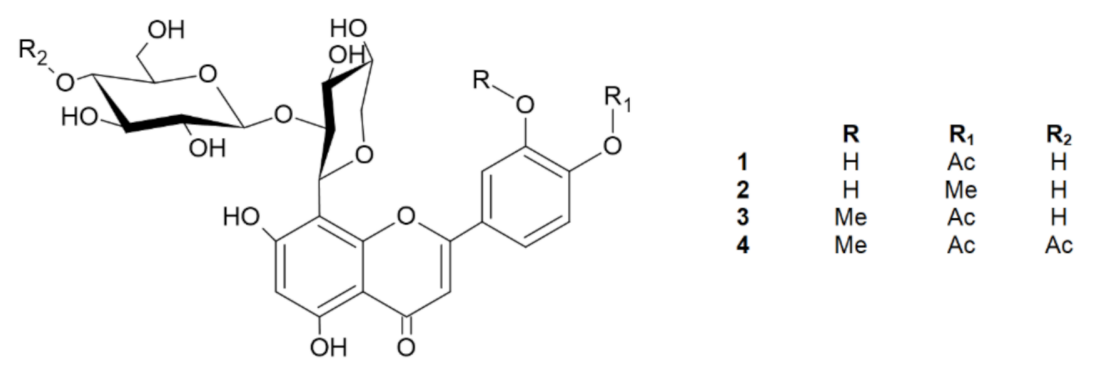

Figure 1. Chemical structures of compounds 1-4.

\subsection{5,7,3'-Trihydroxy-4'-acetoxyflavone-8-C- $\beta$-D-xylopyranoside- $2^{\prime \prime}-O$-glucoside (1)}

Compound 1 was obtained as yellow amorphous powder. Based on the HRESIMS ion peak at $m / z 623[\mathrm{M}+\mathrm{H}]^{+}$, the molecular formula of $\mathrm{C}_{28} \mathrm{H}_{30} \mathrm{O}_{16}$ was determined. The UV spectrum exhibited absorption maxima at 248 and $305 \mathrm{~nm}$, which is typical of flavones. A free C7 hydroxyl group was confirmed by a bathochromic shift of $6 \mathrm{~nm}$ (in the presence of sodium acetate ( $\mathrm{NaOAc})$ ), and a free $\mathrm{C} 5$ hydroxyl group was indicated by a bathochromic shift of $41 \mathrm{~nm}$ (in the presence of aluminum chloride $\left(\mathrm{AlCl}_{3}\right)$ ). Furthermore, a bathochromic shift of $4 \mathrm{~nm}$ (in the presence of sodium methoxide (NaOMe)) indicated that $\mathrm{C}^{\prime}$ is substituted [11]. The ${ }^{1} \mathrm{H}$ NMR spectrum showed one proton singlet at $\delta 6.20$ characterizing a trisubstituted A-ring, while the absence of aromatic methine carbon signals in the range of 90-96 ppm suggested that C8 was substituted. Based on the HMBC data, the proton at $\delta 6.19$ showed correlations with $C 5$ and C8; thus, this signal was assigned to $\mathrm{C} 6[3,12]$. Detailed analysis of the ${ }^{13} \mathrm{C}$ NMR data led to the assignment of the carbons in the B-ring. The signals at $\delta 7.42(1 \mathrm{H}, \mathrm{d}, J=8.28 \mathrm{~Hz})$ and $\delta 6.92(1 \mathrm{H}, \mathrm{d}, J=8.28 \mathrm{~Hz})$ were assigned to $\mathrm{H}-\mathrm{C} 5^{\prime}$ and $\mathrm{H}-\mathrm{C} 6^{\prime}$, respectively, and these assignments were confirmed by COSY correlations. Moreover, the carbon signals at $\delta 150.90\left(\mathrm{C}^{\prime}\right)$ and $\delta 146.92\left(\mathrm{C}^{\prime}\right)$ display ortho coupling, as found in $3^{\prime}, 4^{\prime}$-oxygenated flavonoids [13]. The presence of the unsaturated bond was shown by the $\delta 184.17$ signal in the ${ }^{13} \mathrm{C}$ NMR spectrum, which corresponds to $\mathrm{C} 4$ of the $\mathrm{C}$-ring $[3,14]$. From the HMBC analysis, the $\mathrm{C} 4$ carbon signal was linked with the proton signal at $\delta 6.51$ assigned as H-C3. The presence of an acetoxy group in the structure at $\mathrm{C}^{\prime}{ }^{\prime}$ was revealed by the chemical shift of the $-\mathrm{CH}_{3}$ group in the ${ }^{1} \mathrm{H}$ NMR spectrum at $\delta 1.98(\mathrm{~s}, 3 \mathrm{H})$, as well as in the ${ }^{13} \mathrm{C}$ NMR spectrum for an acetoxyl carbonyl carbon at $\delta 172.98$ and an acetoxyl methyl carbon at $\delta 20.79[3,13]$. This conclusion was further supported by HSQC and HMBC correlations. The ${ }^{1} \mathrm{H}$ NMR spectrum revealed the two anomeric protons at $\delta 5.08(1 \mathrm{H}, \mathrm{d}, J=9.54 \mathrm{~Hz})$ and $\delta 4.29(1 \mathrm{H}, \mathrm{d}, J=7.78 \mathrm{~Hz})$, which are characteristic of two sugars with $\beta$-configurations [15]. Based on the HMBC and HSQC correlations, the anomeric carbons appeared at $\delta 74.90$ and $\delta 105.90$. Extensive analysis of the ${ }^{1} \mathrm{H} \mathrm{NMR},{ }^{13} \mathrm{C}$ NMR, DEPT, and 2D NMR spectral data, including COSY, HSQC, and HMBC, found the individual saccharide chemical shifts that are shown in Table 1 and Figure 2 [13]. According to the obtained data, one of the saccharides was $\beta$-D-glucose, and the second was $\beta$-D-xylopyranoside $[4,14,16]$. One sugar (terminal) was also analyzed by thin-layer chromatography (TLC) after acid hydrolysis of compound 1 and was determined to be glucose. Interference between $\mathrm{H}-\mathrm{C}^{\prime \prime \prime}$ and $\mathrm{H}-\mathrm{C} 2^{\prime \prime}$, as well as 
$\mathrm{H}-\mathrm{C} 1^{\prime \prime}$ and $\mathrm{C} 8$ from the $\mathrm{HMBC}$ data, suggests that the sugars are linked by $\mathrm{Glc}\left(1^{\prime \prime \prime} \rightarrow 2^{\prime \prime}\right) \mathrm{Xyl}$ bonds. Moreover, the type of bonds and substitutions were confirmed based on triplequadrupole MS fragmentation. The ion fragmentation pattern of flavonoids shows a retro-Diels-Alder reshuffling in the C-ring with the loss of neutral molecules of water, saccharides, and methyl and carbonyl groups [17]. Compound $\mathbf{1}$ showed a predominant molecular ion at $m / z 621[\mathrm{M}-\mathrm{H}]^{-}$. Other fragments were as follows $(\mathrm{CE}=-20 \mathrm{eV})$ : 399 [M-H-glucose-OAc], which indicated the presence of the neutral loss of hexose and an acetoxy group from the structure; 309 [M-H-glucose-OAc-part of xylose]; and 175 [M$\mathrm{H}$-glucose-OAc-part of xylose- $\mathrm{C}_{8} \mathrm{H}_{6} \mathrm{O}-\mathrm{OH}$ ]. The loss of $\mathrm{C}_{8} \mathrm{H}_{6} \mathrm{O}$ suggests that $\mathrm{C} 3$ (of the C-ring) is not substituted with a hydroxyl group. On the other hand, the loss of this moiety may indicate a hydroxyl group at $\mathrm{C}^{\prime}$ (of the B-ring) [17]. Moreover, the IR spectrum showed typical signals for $\mathrm{O}-\mathrm{H}\left(\mathrm{V}_{\max } 3462\right), \mathrm{C}-\mathrm{H}\left(\mathrm{V}_{\max } 2950\right), \mathrm{C}=\mathrm{O}\left(\mathrm{V}_{\max } 1716\right)$, and $\mathrm{C}=\mathrm{C}$ $\left(\mathrm{V}_{\max } 1616\right)$ [17]. Therefore, the new chemical structure from plants, $5,7,3^{\prime}$-trihydroxy-4'acetoxyflavone-8-C- $\beta$-D-xylopyranoside- $2^{\prime \prime}$-O-glucoside (Figure 1 ) named scleranthoside A, was definitively established.

Table 1. ${ }^{1} \mathrm{H}$ and ${ }^{13} \mathrm{C}$ spectral data of $\mathbf{1}, \mathbf{2}$, and $4\left(\mathrm{CD}_{3} \mathrm{OD}, 400 \mathrm{~Hz}, \delta\right.$ in ppm, $J$ in $\left.\mathrm{Hz}\right)$.

\begin{tabular}{|c|c|c|c|c|c|c|}
\hline \multirow{2}{*}{ C No. } & \multicolumn{2}{|r|}{1} & \multicolumn{2}{|r|}{2} & \multicolumn{2}{|r|}{4} \\
\hline & $\delta_{C}$ & $\delta_{H}$ & $\delta_{C}$ & $\delta_{H}$ & $\delta_{C}$ & $\delta_{H}$ \\
\hline 2 & 166.36 & - & 166.21 & - & 164.80 & - \\
\hline 3 & 104.46 & $6.51, s$ & 104.24 & $6.61, s$ & 104.01 & $6.60, s$ \\
\hline 4 & 184.17 & - & 184.25 & - & 182.79 & - \\
\hline 5 & 162.62 & - & 162.82 & - & 161.27 & - \\
\hline 6 & 100.86 & $6.19, s$ & 100.78 & $6.27, s$ & 99.47 & $6.21, s$ \\
\hline 7 & 164.55 & - & 164.56 & - & 163.27 & - \\
\hline 8 & 103.92 & - & 104.38 & - & 102.09 & - \\
\hline 9 & 156.89 & - & 156.95 & - & 155.51 & - \\
\hline 10 & 105.36 & - & 105.48 & - & 106.32 & - \\
\hline -OMe & - & - & 56.69 & $4.01(s, 3 \mathrm{H})$ & 55.31 & $4.03(s, 3 \mathrm{H})$ \\
\hline & 172.98 & - & - & - & 170.29 & - \\
\hline -OAc & 20.79 & $1.98, s$ & - & - & 19.08 & $1.93, s$ \\
\hline $1^{\prime}$ & 124.16 & - & 124.13 & - & 122.81 & - \\
\hline $2^{\prime}$ & 114.50 & $7.68, s$ & 111.03 & $7.61, s$ & 109.71 & $7.66, s$ \\
\hline $3^{\prime}$ & 146.92 & - & 149.45 & - & 148.09 & - \\
\hline $4^{\prime}$ & 150.90 & - & 151.88 & - & 150.52 & - \\
\hline $5^{\prime}$ & 116.85 & $6.92(d, J=8.28)$ & 117.07 & $6.96(d, J=8.28)$ & 115.41 & $6.96(d, J=8.28)$ \\
\hline $6^{\prime}$ & 120.78 & $7.42(d, J=8.28)$ & 121.84 & $7.50(d, J=8.28)$ & 120.41 & $7.51(d, J=8.28)$ \\
\hline $1^{\prime \prime}$ & 74.90 & $5.08(d, 1 \mathrm{H}, J=9.54)$ & 76.02 & $5.10(d, 1 \mathrm{H}, J=9.54)$ & 71.40 & $5.14(d, 1 \mathrm{H}, J=9.54)$ \\
\hline $2^{\prime \prime}$ & 81.66 & 3.99 & 81.36 & 3.85 & 81.52 & 3.87 \\
\hline $3^{\prime \prime}$ & 75.95 & 3.76 & 77.11 & 3.76 & 73.34 & 3.85 \\
\hline $4^{\prime \prime}$ & 70.17 & 4.20 & 70.22 & 3.89 & 68.60 & 3.91 \\
\hline $5^{\prime \prime}$ & 71.92 & 4.06 & 72.09 & 3.87 & 70.58 & 3.90 \\
\hline $1^{\prime \prime \prime}$ & 105.89 & $4.29(d, 1 \mathrm{H}, J=7.78)$ & 105.98 & $4.31(d, 1 \mathrm{H}, J=7.78)$ & 104.88 & $4.34(d, 1 \mathrm{H}, J=7.78)$ \\
\hline $2^{\prime \prime \prime}$ & 74.90 & 2.91 & 76.02 & 3.15 & 71.40 & 3.33 \\
\hline $3^{\prime \prime \prime}$ & 77.76 & 3.01 & 77.98 & 3.19 & 74.64 & 3.37 \\
\hline $4^{\prime \prime \prime}$ & 70.67 & 2.93 & 71.82 & 3.17 & 69.68 & 3.23 \\
\hline $5^{\prime \prime \prime}$ & 75.57 & 3.15 & 75.88 & 3.27 & 71.40 & 3.38 \\
\hline $6^{\prime \prime}$ & 64.58 & 3.17 & 63.12 & 3.37 & 61.60 & 3.41 \\
\hline \multirow{2}{*}{-OAc } & - & - & - & - & 171.26 & - \\
\hline & - & - & - & - & 19.58 & $1.96, \mathrm{~s}$ \\
\hline
\end{tabular}



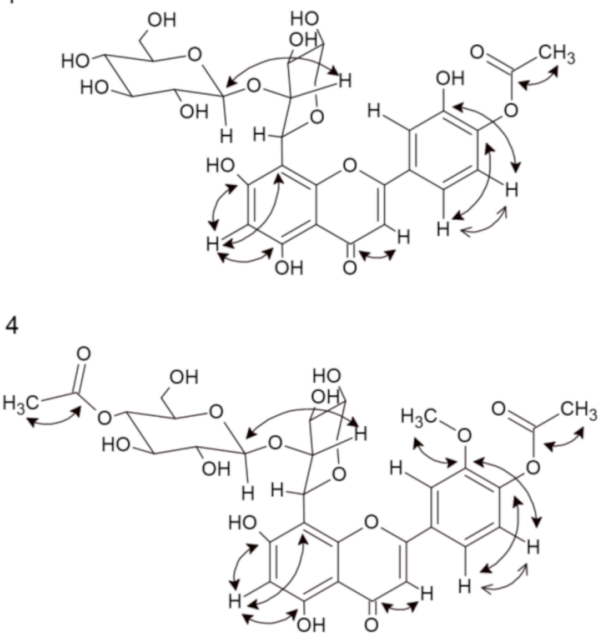

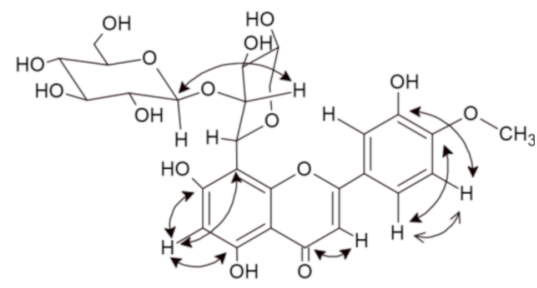

Figure 2. Important ${ }^{1} \mathrm{H}-{ }^{1} \mathrm{H}$ COSY and $\mathrm{HMBC}$ correlation of compounds 1, 2, and 4.

\subsection{5,7,3'-Trihydroxy-4'-methoxyflavone-8-C- $\beta$-D-xylopyranoside-2" $-O$-glucoside (2)}

Compound 2 was also isolated as a yellow amorphous powder. Its molecular formula of $\mathrm{C}_{27} \mathrm{H}_{30} \mathrm{O}_{15}$ was established based on the positive HRESIMS ion peak at $m / z 595[\mathrm{M}+\mathrm{H}]^{+}$. Detailed analysis of the ${ }^{1} \mathrm{H}$ NMR and ${ }^{13} \mathrm{C}$ NMR data (Table 1), including the $2 \mathrm{D}$ techniques COSY, HMBC, and HSQC, of compound 2 showed that its planar structure and sugar side chain were identical to those of compound 1, but some slight differences in chemical shifts were observed, mainly concerning the $C 4^{\prime}$ moiety. The ${ }^{1} \mathrm{H}$ NMR spectrum showed a signal at $\delta 4.01(\mathrm{~s}, 3 \mathrm{H})$ corresponding to the $-\mathrm{CH}_{3}$ instead of the acetoxy group observed in compound 1. Furthermore, the ${ }^{13} \mathrm{C}$ NMR data confirmed the methoxyl group at $\delta 56.84$ [13], which was assigned to the $4^{\prime}$ carbon in the C-ring. The site of methylation was further supported by the HMBC data observed for $\mathrm{C}^{\prime}(\delta$ 151.88) with a methyl group $(\delta 4.01)$ (Figure 2). Compound 2 showed a major molecular ion at $m / z 593[\mathrm{M}-\mathrm{H}]^{-}(\mathrm{CE}=-20 \mathrm{eV})$. In the negative ESI mass spectrum, the fragment at $m / z 413$ [M-glucose-H] corresponded to the subsequent loss of the hexose moiety at the terminal position, and the neutral loss at $m / z 398$ [M-glucose- $\mathrm{H}-\mathrm{CH}_{3}$ ] indicated the loss of a $-\mathrm{CH}_{3}$ moiety. Additionally, the IR spectrum showed characteristic signals for O-H ( $\left.V_{\max } 3420\right), C-H\left(V_{\max } 2903\right), C=O$ $\left(V_{\max } 1716\right)$, and $C=C\left(V_{\max } 1654\right)$ [18]. Thus, the structure of 2 , which is a new natural product, was established as $5,7,3^{\prime}$-trihydroxy- $4^{\prime}$-methoxyflavone- $8-C-\beta$-D-xylopyranoside$2^{\prime \prime}$-O-glucoside and named scleranthoside B (Figure 1).

\subsection{5,7-Dihydroxy-3'-methoxy-4'-acetoxyflavone-8-C- $\beta$-D-xylopyranoside-2" -O-glucoside (3)}

Compound 3 showed an $[\mathrm{M}+\mathrm{H}]^{+}$ion at $m / z 637$ in its HRESIMS spectrum, corresponding to the molecular formula $\mathrm{C}_{29} \mathrm{H}_{32} \mathrm{O}_{16}$. This structure exhibited flavone and sugar skeletons similar to those of compounds $\mathbf{1}$ and $\mathbf{2}$ except for the signals at the $3^{\prime}$ and $4^{\prime}$ carbons of the C-ring. The presence of a methoxyl group in the molecule was indicated by a peak in the ${ }^{1} \mathrm{H}$ NMR spectrum at $\delta 4.01$, which appeared as a singlet and integrated to $3 \mathrm{H}$, and in the ${ }^{13} \mathrm{C}$ NMR spectrum it appeared as one signal at $\delta 56.71$. This methoxyl group was placed on carbon $3^{\prime}(\delta 149.50)$ based on the HMBC correlations of this group with $\mathrm{C}^{\prime}$. In addition, from long-range COSY connectivities, the position of the methoxyl group on the B-ring was confirmed due to the cross-peaks from $\mathrm{H} 2^{\prime}(\delta 7.65)$. Furthermore, in the ${ }^{1} \mathrm{H}$ NMR spectrum, we observed a chemical shift for the $-\mathrm{CH}_{3}$ of the acetoxyl group $(\delta 1.94, \mathrm{~s}, 3 \mathrm{H})$, and in the ${ }^{13} \mathrm{C}$ NMR spectrum, signals for an acetoxyl carbonyl carbon at $\delta 172.93$ and an acetoxyl methyl carbon at $\delta 20.73$ were observed, which, according to the HMBC and COSY data, were assigned to the $\mathrm{C}^{\prime}{ }^{\prime}$ position. Compound 3 produced a minor protonated ion at $m / z 635[\mathrm{M}-\mathrm{H}]^{-}$in the negative mode. In addition, the fragment appearing at 413 [M-H-glucose-OAc] $(\mathrm{CE}=-20 \mathrm{eV})$ indicated the presence of the neutral loss of hexose and an acetoxy group from the structure. The $1 \mathrm{D}$ and 2D 
NMR signals of compound 3 are consistent with literature data [3]. Based on the above observations, the dominant structure in the EtOAc fraction, compound 3, was established as 5,7-dihydroxy-3'-methoxy- $4^{\prime}$-acetoxyflavone-8-C- $\beta$-D-xylopyranoside-- $2^{\prime \prime}$-O-glucoside (Figure 1).

2.4. 5,7-Dihydroxy-3'-methoxy-4'-acetoxyflavone-8-C- $\beta$-D-xylopyranoside- $2^{\prime \prime}-O-\left(4^{\prime \prime \prime}\right.$-acetoxy)glucoside (4)

Compound 4, a yellow amorphous powder, exhibited a predominant ion peak at $\mathrm{m} / \mathrm{z}$ $679[\mathrm{M}+\mathrm{H}]^{+}$in positive mode by HRESIMS, corresponding to the molecular formula $\mathrm{C}_{31} \mathrm{H}_{34} \mathrm{O}_{17}$. This was corroborated by the ${ }^{13} \mathrm{C}$ NMR data, which showed signals for 31 carbons (Table 1). Comparison of the NMR data of $\mathbf{3}$ and $\mathbf{4}$ suggested that their structures were highly similar. The signals in the ${ }^{13} \mathrm{C}$ NMR spectrum revealed two acetoxy groups at $\delta 19.08$ and $\delta 19.58$. The significant difference between the structures of 3 and 4 was the additional acetoxy group at $\mathrm{C}^{\prime \prime \prime}$ in the sugar chain. The presence of this group was further verified by the HMBC correlation of $C 4^{\prime \prime \prime}(\delta 69.68)$ with the methyl acetoxyl carbon, which resonates at $\delta 19.58$ (Figure 2). Additionally, from the HSQC data, carbon $4^{\prime \prime \prime}$ of the glucose chain was linked with the protons of the methyl acetoxyl moiety $(\delta 1.95)$. A product ion scan revealed that compound 4 produced a minor protonated ion at $m / z 677[\mathrm{M}-\mathrm{H}]^{-}$in the negative mode. In addition, the fragment appearing at $m / z 413$ [M-H-glucose-OAc] $(\mathrm{CE}=-20 \mathrm{eV})$ indicated the presence of the neutral loss of hexose and an acetoxyl group from the structure. The high-energy ion fragmentation pathway $(\mathrm{CE}=-70 \mathrm{eV})$ showed $\mathrm{m} / \mathrm{z}$ 59 , which may indicate an ion for the second acetoxyl group. Moreover, the IR spectrum showed typical signals for $\mathrm{O}-\mathrm{H}\left(\mathrm{V}_{\max } 3420\right), \mathrm{C}-\mathrm{H}\left(\mathrm{V}_{\max } 2899\right), \mathrm{C}=\mathrm{O}\left(\mathrm{V}_{\max } 1732\right)$, and $\mathrm{C}=\mathrm{C}$ $\left(\mathrm{V}_{\max } 1656\right.$ ) [18]. Hence, the structure of 4 was identified as 5,7-dihydroxy-3'-methoxy-4'acetoxyflavone-8-C- $\beta$-D-xylopyranoside- $2^{\prime \prime}-O-\left(4^{\prime \prime \prime}\right.$-acetoxy $)$-glucoside and this compound was given the trivial name scleranthoside $C$ (Figure 1).

\subsection{Apiopaenonside (5)}

Compound $\mathbf{5}$ was obtained as a yellow amorphous powder. The molecular formula $\mathrm{C}_{20} \mathrm{H}_{28} \mathrm{O}_{12}$ was deduced from its positive mode HRESIMS, which showed a molecular ion peak $[\mathrm{M}+\mathrm{H}]^{+}$at $m / z 460$. In the ${ }^{1} \mathrm{H}$ NMR spectrum, the peaks between $\delta 6.50$ and $\delta 8.00$ correspond to hydrogen atoms in the aromatic ring. Furthermore, the signals at $\delta 7.68$, $\delta 7.58$, and $\delta 7.23$ indicate the presence of substitutions on $\mathrm{C} 1, \mathrm{C} 2$, and C4, respectively [13]. Furthermore, HSQC correlations verified the $\delta 124.6$ (C1), 112.4 (C2), and 116 (C4) signals in the ${ }^{13} \mathrm{C}$ spectrum. In addition, a singlet at $\delta 2.58$ indicated the presence of a $\mathrm{CH}_{2}$ group, where the hydrogens do not interact with any other protons. Based on chromatographic, spectral analysis and the literature data, compound $\mathbf{5}$ was established as apiopaenonside (Figure 3), which was previously isolated from Paeonia suffruticosa $[19,20]$.<smiles>COc1ccc(C(C)=O)c(OC2O[C@H](COC3OC[C@](O)(CO)[C@H]3O)[C@@H](O)[C@H](O)[C@H]2O)c1</smiles>

Figure 3. Chemical structure of compound 5. 
Compounds 1-5 were evaluated for their anti-collagenase activity. As shown in Table 2, the highest inhibitory activity was possessed by 5,7-dihydroxy-3'-methoxy- $4^{\prime}$ acetoxyflavone-8-C- $\beta$-D-xylopyranoside- $2^{\prime \prime}-O-\left(4^{\prime \prime \prime}\right.$-acetoxy)-glucoside $(4)$ with an $\mathrm{IC}_{50}$ (median inhibitory concentration) value of $36.06 \mu \mathrm{M}$, compared to epigallocatechin gallate (34.32 $\mu \mathrm{M})$.

Table 2. Anti-collagenase activity of compounds 1-5 and their respective $\mathrm{IC}_{50}$ values.

\begin{tabular}{cc}
\hline Compounds & IC $_{\mathbf{5 0}}{ }^{\mathbf{a}}(\boldsymbol{\mu M})$ \\
\hline $\mathbf{1}$ & $70.24 \pm 1.37$ \\
$\mathbf{2}$ & $64.86 \pm 1.08$ \\
$\mathbf{3}$ & $48.28 \pm 1.05$ \\
$\mathbf{4}$ & $36.06 \pm 0.78$ \\
$\mathbf{5}$ & $>125$ \\
EGCG $^{\mathrm{b}}$ & $34.32 \pm 0.21$
\end{tabular}

a All data are represented as the mean of $\mathrm{IC}_{50}$ values with standard deviation from triplicate measurement;

b Positive control.

\section{Materials and Methods}

\subsection{General Experimental Procedures}

Acetonitrile Optima (ACN), was purchased from Fisher Chemical (Loughborough, UK). Ultra-pure water (UPW) was obtained using the POLWATER DL3-100 system (Kraków, Poland). Petrol, chloroform $\left(\mathrm{CHCl}_{3}\right)$, ethyl acetate (EtOAc), diethyl ether $\left(\mathrm{Et}_{2} \mathrm{O}\right)$, $n$-butanol $(\mathrm{BuOH})$, formic acid (FA), hydrochloric acid $(\mathrm{HCl})$, acetic acid $(\mathrm{AcOH})$, dimethyl sulfoxide (DMSO), ammonia solution $25 \%\left(\mathrm{NH}_{4} \mathrm{OH}\right)$, ethanol $(\mathrm{EtOH})$, and methanol $(\mathrm{MeOH})$ were purchased from POCH (Gliwice, Poland). Natural product reagent A (NA) was purchased from Carl Roth (Karlsruhe, Germany). To prepare aniline phthalate, phthalic acid was purchased from Sigma-Aldrich (Poole, Great Britain) and aniline from Chempur (Piekary Ślaskie, Poland). Epigallocatechin gallate (EGCG) as a positive control was obtained from Cayman Chemical (Ann Arbor, MI, USA). Collagenase from Clostridium histolyticum (C0130), sodium chloride $(\mathrm{NaCl})$, calcium chloride $\left(\mathrm{CaCl}_{2}\right)$, and $\mathrm{N}-[3-(2-\mathrm{Furyl})$ acryloyl]-leugly-Pro-Ala (FALGPA) were obtained from Sigma-Aldrich (Poole, UK). Monosaccharides for TLC analysis of the hydrolysis products (glucose, xylose, rhamnose) were purchased from Merck KGaA (Darmstadt, Germany), and uronic acids (glucuronide acid, galacturonide acid) were purchased from Cayman Chemical (Ann Arbor, MI, USA). Luteolin (purity $>96 \%$ ) was isolated from the inflorescences of Arctium tomentosum [21]. Sephadex LH-20 was provided by GE Healthcare Bio-Sciences AB (Uppsala, Sweden). TLC plates coated with silica gel (105554) and microcrystalline cellulose (105716) were purchased from Merck KGaA (Darmstadt, Germany). LC-MS analyses were conducted using an Agilent Technologies 1260 Infinity chromatography system connected to a 6230 time-of-flight (TOF) mass spectrometer (Santa Clara, CA, USA). Preparative HPLC analyses were carried out on a Shimadzu instrument (Columbia, MD, USA) with LC20-AP pumps, an SPD-10ATvp detector, an LC-10AF autosampler, and an FRC-10A fraction collector. Liquid chromatography triple-quadrupole mass spectrometry was performed on a Shimadzu LC-MS 8050 Triple Quad spectrometer coupled with a Nexera LC system (Kyoto, Japan) consisting of an SCL-40 system controller, a DGU-405 degasser, an LC-40D xR pump, a CTO-40S column oven, and an SIL-40C xR autosampler. UV spectra were measured with an Analytic Jena SPECORD 200 Plus instrument (Jena, Germany). Melting points were obtained using a BUCHI 535. Column chromatography (CC) was performed with a Sephadex LH-20 column. IR spectra were recorded on a Perkin Elmer FT-IR spectrometer spectrum-2000 (Waltham, MA, USA) using potassium bromide (KBr) pellets. NMR spectra were recorded on a Thermo Fisher Scientific Bruker Avance II 400 spectrometer (Waltham, MA, USA) at $400 \mathrm{MHz}$ in deuterated methanol $\left(\mathrm{CD}_{3} \mathrm{OD}\right)$. Optical rotations were measured with JASCO P-2000 (Tokyo, Japan). Bioassay was performed on BioTek Instruments microplate spectrophotometer EPOCH 2 (Oxfordshire, UK). 


\subsection{Plant Material}

The aerial parts of Scleranthus perennis were collected between August and September 2018 in the Bialystok area $\left(53^{\circ} 06^{\prime} 39.0^{\prime \prime}\right.$ N 23 $\left.07^{\prime} 13.4^{\prime \prime} \mathrm{E}\right)$ in Poland. The plant was authenticated based on its morphological characteristics by one of the authors (MT) according to Rutkowski [22]. A plant voucher specimen (No. SP-18041) was deposited in the Herbarium of the Department of Pharmacognosy at the Medical University of Białystok, Poland.

\subsection{Extraction and Isolation}

The dried and powdered aerial parts of S. perennis (1100 g) were partitioned successively with petrol, chloroform, and methanol. The $\mathrm{MeOH}$ extract was concentrated to dryness under vacuum at a controlled temperature $\left(30 \pm 2{ }^{\circ} \mathrm{C}\right)$ and subjected to lyophilization until a constant weight was obtained (108 g). The extract was dissolved in $\mathrm{MeOH}$ $(110 \mathrm{~g})$ and subjected to CC $(85 \mathrm{~cm} \times 5 \mathrm{~cm})$ on a Sephadex LH-20 column. The column was eluted with $\mathrm{MeOH}$ to give 33 fractions ( $\sim 50 \mathrm{~mL}$ each). Based on TLC silica gel plate developed with EtOAc: $\mathrm{H}_{2} \mathrm{O}: \mathrm{FA}$ at a ratio of 18:1:1 and derivatized with 1\% NA and LC-MS analyses (UPW:ACN $5 \rightarrow 95$ ), all fractions were pooled into five main fractions (F1-F5). The aqueous residue of $\mathrm{F} 3$ was fractionated by liquid-liquid extraction with $\mathrm{Et}_{2} \mathrm{O}, \mathrm{EtOAc}$, and finally $n-\mathrm{BuOH}$. The combined layers were evaporated and purified. LC-MS analysis of the EtOAc fraction showed compounds that could be classified as derivatives of flavonoids. The EtOAc fraction $(2 \mathrm{~g})$ was dissolved in DMSO, and part of this fraction (2.5 g) was separated by preparative HPLC (0-35 $\mathrm{min}, 0 \%-7 \%$ UPW-ACN, $20 \mathrm{~mL} / \mathrm{min})$ to obtain compound $\mathbf{1}(11.75 \mathrm{mg})$, compound $\mathbf{2}$ (13.8 mg), compound 3 (385.56 mg), compound 4 (31.3 $\mathrm{mg})$, and compound $5(8.69 \mathrm{mg})$. The purified compounds were identified based on chromatographical products of acid hydrolysis (TLC; Rf: 0.55 corresponds to glucose standard) and the recorded ${ }^{1} \mathrm{H},{ }^{13} \mathrm{C}$, COSY, HSQC, and $\mathrm{HMBC}$ spectra in $\mathrm{CD}_{3} \mathrm{OD}$, as well as MS, IR, and UV spectra, and the product ion scan.

\subsection{Acid Hydrolysis}

Approximately $3 \mathrm{mg}$ of compounds 1-4 was refluxed in $2 \mathrm{~N} \mathrm{HCl}(5 \mathrm{~mL})$ for $2 \mathrm{~h}$. The aglycones from the post-hydrolyzed solution (PHS) were extracted with $\mathrm{Et}_{2} \mathrm{O}$ and identified by TLC with standard. The TLC plate was developed with 30:3:10 solvent system ( $\mathrm{HCl}: \mathrm{AcOH}: \mathrm{H}_{2} \mathrm{O}$ ). TLC analysis of monosaccharides residues was conducted by spotting standards, the PHS water layer, and developing with a solvent system of 20:1:4 (EtOH: $\mathrm{NH}_{4} \mathrm{OH}: \mathrm{H}_{2} \mathrm{O}$ ). TLC chromatograms were derivatized using freshly prepared aniline phthalate, heating, and comparing with Rf values of standards.

\subsection{Isolates}

5,7,3'-trihydroxy-4'-acetoxyflavone-8-C- $\beta$-D-xylopyranoside- $2^{\prime \prime}$-O-glucoside (1): yellow amorphous powder (mp.: $188.5-189.0^{\circ} \mathrm{C}$ ); $[\alpha]_{\mathrm{D}}+21.1$ (DMSO; c 0.1); HPLC rt, $48.1 \mathrm{~min}$; HRESIMS $m / z=623.18[\mathrm{M}+\mathrm{H}]^{+}$(calculated for $\mathrm{C}_{28} \mathrm{H}_{30} \mathrm{O}_{16}$ ); UV $\lambda_{\max } \mathrm{nm}$ : 254, 305; +NaOMe: 253, 309; $+\mathrm{AlCl}_{3}$ : 254, 346; +NaOAc: 254, 311; $+\mathrm{H}_{3} \mathrm{BO}_{3}$ : 248, 320; IR $V_{\max }(\mathrm{KBr})$ 3462 (s, O-H), 2950 (s, C-H), 1716 (s, C=O), 1616 (s, C=C); NMR spectral data, see Table 1 and Figures S1-S9 in the Supplementary Materials.

$5,7,3^{\prime}$-trihydroxy-4'-methoxyflavone-8-C- $\beta$-D-xylopyranoside- $2^{\prime \prime}$-O-glucoside (2): yellow amorphous powder (mp.: $178.5-179.2^{\circ} \mathrm{C}$ ); $[\alpha]_{\mathrm{D}}-9.2$ (DMSO; c 0.1) HPLC rt, $51.2 \mathrm{~min}$; HRESIMS $m / z=595.18[\mathrm{M}+\mathrm{H}]^{+}$(calculated for $\mathrm{C}_{27} \mathrm{H}_{30} \mathrm{O}_{15}$ ); UV $\lambda_{\max } \mathrm{nm}$ : 248, 288; +NaOMe: 252, 302; + $\mathrm{AlCl}_{3}$ : 251, 316; +NaOAc: 257, 303; $+\mathrm{H}_{3} \mathrm{BO}_{3}$ : 250, 298; IR $V_{\max }(\mathrm{KBr})$ 3420 (s, O-H), 2903 (s, C-H), 1716 (s, C=O), 1654 (s, C=C); NMR spectral data, see Table 1 and Figures S10-S18 in the Supplementary Materials.

5,7-dihydroxy-3'-methoxy-4'-acetoxyflavone-8-C- $\beta$-D-xyloside-2 ${ }^{\prime \prime}$-O-glucoside (3): yellow amorphous powder; HPLC rt, $55.2 \mathrm{~min}$; HRESIMS $m / z=637.18[\mathrm{M}+\mathrm{H}]^{+}$(calculated for $\mathrm{C}_{30} \mathrm{H}_{31} \mathrm{O}_{16}$ ); $\mathrm{UV} \lambda_{\max } \mathrm{nm}$ : 253, 271, 347; +NaOMe: 266, 404; $+\mathrm{AlCl}_{3}: 277,392 ;+\mathrm{NaOAc}$ : 273,$352 ;+\mathrm{H}_{3} \mathrm{BO}_{3}: 212,346$; NMR spectral data, see [2] and Figures S19-S23 in the Supplementary Materials. 
5,7-dihydroxy-3'-methoxy-4'-acetoxyflavone-8-C- $\beta$-D-xylopyranoside- $2^{\prime \prime}-O-\left(4^{\prime \prime \prime}\right.$-aceto xy)-glucoside (4): yellow amorphous powder (mp.: $\left.164.6-166.2{ }^{\circ} \mathrm{C}\right) ;[\alpha]_{\mathrm{D}}+10.6(\mathrm{DMSO}$; c 0.5); HPLC rt, $60.4 \mathrm{~min}$; HRESIMS $m / z=679.22[\mathrm{M}+\mathrm{H}]^{+}$(calculated for $\mathrm{C}_{31} \mathrm{H}_{34} \mathrm{O}_{17}$ ); UV $\lambda_{\max }$ nm: 253, 287; +NaOMe: 251, 304; +AlCl $: 249,320 ;+\mathrm{NaOAc}: 259,304 ;+\mathrm{H}_{3} \mathrm{BO}_{3}: 263$, 301; IR $V_{\max }(\mathrm{KBr}) 3420$ (s, O-H), 2899 (s, C-H), 1732 (s, C=O), 1656 (s, C=C); NMR spectral data, see Table 1 and Figures S24-S32 in the Supplementary Materials.

Apiopaenonside (5): yellow amorphous powder; HPLC rt, $18.6 \mathrm{~min}$; HRESIMS $m / z=460[\mathrm{M}+\mathrm{H}]^{+}$(calculated for $\mathrm{C}_{20} \mathrm{H}_{28} \mathrm{O}_{12}$ ); UV $\lambda_{\max }$, see [19], NMR spectral data, see [20].

\subsection{In Vitro Collagenase Inhibition Assay}

The previous spectrophotometric procedure was modified and subsequently employed to determine the anti-collagenase activity of the isolated compounds [23]. This assay was performed in $50 \mathrm{mM}$ Tricine buffer $\left(\mathrm{pH}=7.5 ; 400 \mathrm{mM} \mathrm{NaCl}, 10 \mathrm{mM} \mathrm{CaCl}_{2}\right)$. The mixed solution included $25 \mu \mathrm{L}$ of $0.1 \mathrm{U} / \mathrm{mL}$ collagenase from Clostridium histolyticum, $25 \mu \mathrm{L}$ Tricine buffer, and $25 \mu \mathrm{L}$ of various levels of the sample were incubated at $37^{\circ} \mathrm{C}$ for $20 \mathrm{~min}$. After incubation, $75 \mu \mathrm{L}$ of $0.8 \mathrm{mM}$ FALGPA substrate was present. Then, absorbance was measured at $335 \mathrm{~nm}$ wavelength. Negative control was performed using Tricine buffer instead of sample and positive control was conducted with EGCG.

The percentage inhibition for assay was calculated by:

$$
\text { Enzyme inhibition activity }(\%)=[1-(\mathrm{C} / \mathrm{S})] \times 100 \%
$$

where $C$ is the negative control and $S$ is the sample.

\subsection{Statistical Analysis}

All results are expressed as the mean \pm standard deviation (SD) and analyses were performed in triplicate. Significant statistical analysis was performed using GraphPad Prisma 9 software (GraphPad Software, San Diego, CA, USA). Statistical differences were assessed using one-way ANOVA.

\section{Conclusions}

The occurrence of 1-4 constitutes this as the first report of flavone $C$-glycosides from the Scleranthus perennis. Compound 5, a derivative of paeonol, was also newly found in the Caryophyllaceae family. Furthermore, to the best of our knowledge, compounds 1, 2, and 4 are new chemical structures occurring in the plant kingdom. Their discovery not only extends the structural and chemical diversity of phenolic compound, but also underlines the potential source for bioactive natural products. Further investigations on their biological activities are in progress.

Supplementary Materials: The following are available online, Figure S1: Product ion scan in positive mode of 1; Figure S2: Product ion scan in negative mode of 1; Figure S3: UV spectrum of 1; Figure S4: IR spectrum of 1 in $\mathrm{KBr}$; Figure S5: ${ }^{1} \mathrm{H}$ NMR spectrum (400 MHz) of $\mathbf{1}$ in $\mathrm{CD}_{3} \mathrm{OD}$; Figure S6: ${ }^{13} \mathrm{C}$ NMR spectrum (400 MHz) of 1 in $\mathrm{CD}_{3} \mathrm{OD}$; Figure S7: ${ }^{1} \mathrm{H}-{ }^{1} \mathrm{H}$ COSY spectrum of $\mathbf{1}$ in $\mathrm{CD}_{3} \mathrm{OD}$; Figure S8: HSQC spectrum of 1 in $\mathrm{CD}_{3} \mathrm{OD}$; Figure S9: HMBC spectrum of 1 in $\mathrm{CD}_{3} \mathrm{OD}$; Figure S10: Product ion scan in positive mode of 2; Figure S11: Product ion scan in negative mode of 2; Figure S12: UV spectrum of 2; Figure S13: IR spectrum of 2 in KBr; Figure S14: ${ }^{1} \mathrm{H}$ NMR spectrum $(400 \mathrm{MHz})$ of 2 in $\mathrm{CD}_{3} \mathrm{OD}$; Figure S15: ${ }^{13} \mathrm{C}$ NMR spectrum (400 MHz) of 2 in $\mathrm{CD}_{3} \mathrm{OD}$; Figure S16: ${ }^{1} \mathrm{H}-{ }^{1} \mathrm{H}$ COSY spectrum of 2 in $\mathrm{CD}_{3} \mathrm{OD}$; Figure S17: HSQC spectrum of 2 in $\mathrm{CD}_{3} \mathrm{OD}$; Figure S18: HMBC spectrum of 2 in $\mathrm{CD}_{3} \mathrm{OD}$; Figure S19: ${ }^{1} \mathrm{H}$ NMR spectrum $(400 \mathrm{MHz})$ of 3 in $\mathrm{CD}_{3} \mathrm{OD}$; Figure S20: ${ }^{13} \mathrm{C}$ NMR spectrum (400 MHz) of 3 in $\mathrm{CD}_{3} \mathrm{OD}$; Figure S21: ${ }^{1} \mathrm{H}-{ }^{1} \mathrm{H}$ COSY spectrum of 3 in $\mathrm{CD}_{3} \mathrm{OD}$; Figure S22: HSQC spectrum of 3 in $\mathrm{CD}_{3} \mathrm{OD}$; Figure S23: HMBC spectrum of 3 in $\mathrm{CD}_{3} \mathrm{OD}$; Figure S24: Product ion scan in positive mode of 4; Figure S25: Product ion scan in negative mode of 4; Figure S26: UV spectrum of 4; Figure S27: IR spectrum of 4 in KBr; Figure S28: ${ }^{1} \mathrm{H}$ NMR spectrum (400 MHz) of 4 in $\mathrm{CD}_{3} \mathrm{OD}$; Figure S29: ${ }^{13} \mathrm{C}$ NMR spectrum $(400 \mathrm{MHz})$ of 4 in $\mathrm{CD}_{3} \mathrm{OD}$; Figure S30: ${ }^{1} \mathrm{H}-{ }^{1} \mathrm{H}$ COSY 
spectrum of 4 in $\mathrm{CD}_{3} \mathrm{OD}$; Figure S31: HSQC spectrum of 4 in $\mathrm{CD}_{3} \mathrm{OD}$; Figure S32: HMBC spectrum of 4 in $\mathrm{CD}_{3} \mathrm{OD}$.

Author Contributions: Conceptualization, K.J., J.W.S. and M.T.; methodology, K.J. and J.W.S.; formal analysis, K.J. and M.T.; investigation, K.J., J.W.S. and S.G.; writing—original draft preparation, K.J.; writing-review and editing, M.T. and S.G.; visualization, K.J.; supervision, M.T.; All authors have read and agreed to the published version of the manuscript.

Funding: This research received no external funding.

Institutional Review Board Statement: Not applicable.

Informed Consent Statement: Not applicable.

Data Availability Statement: Data are contained within the article and Supplementary Materials.

Acknowledgments: Special thanks to A. Bajguz and A. Piotrowska-Niczyporuk from the University of Białystok for the accepting authors as visiting scientists and providing a laboratory to conduct the study with a triple-quadrupole LC-MS system. The authors express thanks to Wojciech Miltyk from Medical University of Bialystok for providing the laboratory to conduct IR spectroscopic measurements and Piotr Olejnik for technical assistance in obtaining IR spectra. We also thank to Urszula Sierniewska from the Medical University of Warsaw for her participation in the process of isolation and identification of the compound.

Conflicts of Interest: The authors declare no conflict of interest.

Sample Availability: Samples of the compounds 1-5 are available from the authors.

\begin{tabular}{|c|c|}
\hline NMR & nuclear magnetic resonance \\
\hline COSY & correlation spectroscopy \\
\hline HSQC & heteronuclear single quantum coherence \\
\hline HMBC & heteronuclear multiple bond correlation \\
\hline DEPT & distortionless enhancement by polarization transfer \\
\hline IR & infrared spectroscopy \\
\hline UV & ultraviolet radiation \\
\hline UV-Vis & ultraviolet-visible spectroscopy \\
\hline ESI & electrospray ionization \\
\hline $\mathrm{IC}_{50}$ & median inhibitory concentration \\
\hline MS & mass spectrometer \\
\hline LC-MS & liquid chromatography-mass spectrometry \\
\hline HPLC & high-performance liquid chromatography \\
\hline HRESIMS & high-resolution electrospray ionization mass spectrometry \\
\hline TLC & thin-layer chromatography \\
\hline Glc & glucose \\
\hline Xyl & xylose \\
\hline $\mathrm{NaOAc}$ & sodium acetate \\
\hline $\mathrm{NaOMe}$ & sodium methoxide \\
\hline $\mathrm{AlCl}_{3}$ & aluminum chloride \\
\hline $\mathrm{NaCl}$ & sodium chloride \\
\hline $\mathrm{CaCl}_{2}$ & calcium chloride \\
\hline FALGPA & N-[3-(2-Furyl)acryloyl]-leu-gly-Pro-Ala \\
\hline EGCG & epigallocatechin gallate \\
\hline TOF & time-of-flight \\
\hline $\mathrm{CD}_{3} \mathrm{OD}$ & deuterated methanol \\
\hline DMSO & dimethyl sulfoxide \\
\hline $\mathrm{CC}$ & column chromatography \\
\hline $\mathrm{MeOH}$ & methanol \\
\hline $\mathrm{Et}_{2} \mathrm{O}$ & diethyl ether \\
\hline
\end{tabular}




$\begin{array}{ll}\text { EtOAc } & \text { ethyl acetate } \\ n \text {-BuOH } & n \text {-butanol } \\ \text { UPW } & \text { ultra-pure water } \\ \text { ACN } & \text { acetonitrile } \\ \text { mp } & \text { melting point } \\ \text { SD } & \text { standard deviation } \\ \text { ANOVA } & \text { analysis of variance } \\ \text { PHS } & \text { post-hydrolyzed solution }\end{array}$

\section{References}

1. Smissen, R.D.; Garnock-Jones, P.J. Relationships, classification and evolution of Scleranthus (Caryophyllaceae) as inferred from analysis of morphological characters. Bot. J. Linn. Soc. 2002, 140, 15-29. [CrossRef]

2. Sell, P.D. Scleranthus (Caryophyllaceae). In Flora Europaea, 1st ed.; Tutin, T.G., Heywood, V.H., Burges, N.A., Valentine, D.H., Walters, S.M., Webb, D.A., Eds.; Cambridge University Press: London, UK, 1964; pp. 148-149.

3. Yayli, N.; Seymen, H.; Baltaci, C. Flavone C-glycosides from Scleranthus uncinatus. Phytochemistry 2001, 58, 607-610. [CrossRef]

4. Yayli, N.; Baltaci, C.; Genç, H.; Terzioğlu, S. Phenolic and flavone C-glycosides from Scleranthus uncinatus. Pharm. Biol. 2002, 40, 369-373. [CrossRef]

5. Zdraveva, P. Chemical compounds in butanol extracts of Scleranthus perennis L., Caryophyllaceae. In Proceedings of the 4th Conference on Medicinal and Aromatic Plants of South-East European Countries, Iasi, Romania, 28-31 May 2006.

6. Zdraveva, P.; Assenov, I. Phytochemical study of Scleranthus perennis L. (Caryophyllaceae). Pharmacia 1997, 44, 7-10.

7. Zdraveva, P.; Gevrenova, R.; Dimitrova, B. Phenolic compounds of Scleranthus annuus L. (Caryophyllaceae). In Proceedings of the 3rd Conference on Medicinal and Aromatic Plants of Southeast European Countries, Nitra, Slovak Republic, 5-8 September 2004.

8. Svensson, L. An estimate of pollen carryover by ants in a natural population of Scleranthus perennis L. (Caryophyllaceae). Oecologia 1985, 66, 373-377. [CrossRef] [PubMed]

9. Jakimiuk, K.; Strawa, J.W.; Granica, S.; Tomczyk, M. Flavonoids from the aerial parts of Scleranthus perennis. In Proceedings of the T20 PSE Conference Liverpool 2020 on Contemporary Natural Products Discovery Research, Liverpool, UK, 6 March 2020.

10. Jakimiuk, K.; Wink, M.; Tomczyk, M. Flavonoids of the Caryophyllaceae. Phytochem. Rev. 2021, 20, 1-40. [CrossRef]

11. Mabry, T.J.; Markham, K.R.; Thomas, M.B. The Systematic Identification of Flavonoids; Springer: Berlin/Heidelberg, Germany, 1970.

12. Markham, K.R.; Chari, V.M. Carbon-13 NMR spectroscopy of flavonoids. In The Flavonoids; Harborne, J.B., Mabry, T.J., Eds.; Spriger: Boston, MA, USA, 1970.

13. Agrawal, P.K. Carbon-13 NMR of Flavonoids; Elsevier Science: Amsterdam, The Netherlands, 1982.

14. Chopin, J.; Dellamonica, G. The Flavonoids; Chapman and Hall: London, UK, 1988.

15. Wiliams, C.A.; Harborne, J.B. Flavone and flavanol glycosides. In The Flavonoids. Advances in Research Since 1986; Harborne, J.B., Ed.; Chapman and Hall: London, UK, 1994.

16. Pauli, G.F.; Junior, P. Phenolic glycosides from Adonis aleppica. Phytochemistry 1995, 38, 1245-1250. [CrossRef]

17. Yang, Y.; Sun, X.; Liu, J.; Kang, L.; Chen, S.; Ma, B.; Guo, B. Quantitative and qualitative analysis of flavonoids and phenolic acids in snow chrysanthemum (Coreopsis tinctoria Nutt.) by HPLC-DAD and UPLC-ESI-QTOF-MS. Molecules 2016, 21, 1307. [CrossRef] [PubMed]

18. Barone, V.; Biczysko, M.; Bloino, J. Fully anharmonic IR and Raman spectra of medium-size molecular systems: Accuracy and interpretation. Phys. Chem. Chem. Phys. 2014, 16, 1759-1787. [CrossRef] [PubMed]

19. Li, S.-S.; Wu, Q.; Yin, D.-D.; Feng, C.-Y.; Liu, Z.-A.; Wang, L.-S. Phytochemical variation among the traditional Chinese medicine Mu Dan Pi from Paeonia suffruticosa (tree peony). Phytochemistry 2018, 146, 16-24. [CrossRef] [PubMed]

20. Matsuda, H.; Ohta, T.; Kawaguchi, A.; Yoshikawa, M. Bioactive constituents of Chinese natural medicines. VI.1) Moutan cortex. (2): Structures and radical scavenging effects of suffruticosides A, B, C, D, and E and galloyl-oxypaeoniflorin. Chem. Pharm. Bull. 2001, 49, 69-72. [CrossRef] [PubMed]

21. Strawa, J.; Wajs-Bonikowska, A.; Jakimiuk, K.; Waluk, M.; Poslednik, M.; Nazaruk, J.; Tomczyk, M. Phytochemical examination of woolly burdock Arctium tomentosum leaves and flower heads. Chem. Nat. Compd. 2020, 56, 345-347. [CrossRef]

22. Rutkowski, L. Klucz do Oznaczania Roślin Naczyniowych Polski Niżowej; Wydawnictwo Naukowe PWN: Warsaw, Poland, 2006.

23. Thring, T.S.A.; Hili, P.; Naughton, D.P. Anti-collagenase, anti-elastase and anti-oxidant activities of extracts from 21 plants. BMC Complement. Altern. Med. 2009, 9, 1-11. [CrossRef] [PubMed] 